\title{
Efeito da substituição de pré-secado de capim-tifton 85 por silagem de sorgo no consumo e na digestibilidade dos nutrientes e no desempenho de bovinos de corte ${ }^{1}$
}

\author{
Viviane Glaucia de Souza ${ }^{2}$, Odilon Gomes Pereira ${ }^{3}$, Sebastião de Campos Valadares Filho ${ }^{3}$, Karina \\ Guimarães Ribeiro ${ }^{4}$, Dalton Henrique Pereira ${ }^{5}$, Paulo Roberto Cecon ${ }^{6}$, Salete Alves de Moraes ${ }^{7}$ \\ 1 Parte da tese de doutorado da primeira autora apresentada ao Programa de Pós-Graduação em Zootecnia da Universidade Federal de \\ Viçosa-UFV. Bolsista do CNPq. \\ 2 FACIG, R. Desembargador Alonso Starling, 111, Centro, Manhuaçu-MG, 36900-000 \\ 3 Departamento de Zootecnia/UFV, bolsista do CNPq. \\ ${ }^{4}$ Departamento de Zootecnia/UFVJM. \\ ${ }^{5}$ Doutorando em Zootecnia/UFV. Bolsista da CNPq. \\ ${ }^{6}$ Departamento de Informática/UFV. Bolsista do CNPq. \\ 7 Doutoranda em Ciência Animal/UFMG.
}

RESUMO - Avaliaram-se o consumo e a digestibilidade dos nutrientes, o ganho de peso (GMD) e a conversão alimentar (CA) em bovinos de corte recebendo dietas à base de silagem de sorgo (SS) e pré-secado de capim-tifton 85 como volumoso, nas seguintes proporções: 0:100; 32:68; 66:34 e 100:0, respectivamente, com base na MS. As dietas (isonitrogenadas) foram formuladas para conter aproximadamente $12 \%$ de PB, adotando-se uma relação volumoso:concentrado de 60:40, na MS. Foram utilizados 24 animais mestiços Holandês x Zebu não-castrados (360 kg de PV) distribuídos em um delineamento em blocos casualizados. Após um período de adaptação de 15 dias, foram realizados três períodos experimentais de 28 dias. Para determinação da excreção fecal, utilizou-se a fibra em detergente ácido indigestível (FDAi) como indicador. Os consumos médios diários de MS, MO, PB, EE, CT e NDT, em kg/dia, não foram influenciados pelas dietas, registrando-se valores médios de 9,46; 9,05;1,20;0,52, 7,4 e 6,23 kg/dia, respectivamente. As digestibilidades aparentes da MS, MO, PB e EE foram influenciadas de forma quadrática pelo nível de SS no volumoso, estimando-se digestibilidades mínimas de 60,33; 61,58;61,89 e 55,83\% nos níveis de 44,80; 47,18; 50,95 e 51,21\% de silagem de sorgo, respectivamente. O GMD e a CA foram influenciados de forma quadrática pelos níveis de SS e apresentaram valores máximos e mínimos de 1,25 kg/dia e 7,66 para os níveis de 60,95 e $67,04 \%$ de SS, respectivamente. O uso de silagem pré-secada de capim-tifton 85 associada à silagem de sorgo consistiu em boa alternativa de volumoso para terminação de bovinos de corte. A inclusão de aproximadamente $60 \%$ de silagem de sorgo no volumoso promoveu máximo ganho de peso estimado.

Palavras-chave: confinamento, conversão alimentar, rendimento de carcaça, volumoso

\section{Effect of replacing Tifton 85 haylage with sorghum silage on intake and digestibility of nutrients and performance of beef cattle}

\footnotetext{
ABSTRACT - Intake, digestibility of nutrients, daily weight gain, and feed conversion were evaluated in beef cattle receiving diets containing the following ratios of sorghum silage:Tifton 85 haylage: 0:100;32:68; 66:34; and 100:0. Diets were formulated to be isonitrogenous (12\% crude protein) with a forage:concentrate ratio of 60:40, on DM basis. Twenty-four crossbred Holstein x Zebu steers averaging $360 \mathrm{~kg}$ of initial body weight were distributed in a completely randomized block design with 15 days for diet adaptation followed by three experimental periods of 28 days each. Indigestible acid detergent fiber (IADF) was used to estimate fecal output. Mean daily intakes of DM, OM, CP, EE, TC, and TDN all were not affected by treatments with mean values of: 9.46, 9.05, 1.20, 0.52, 7.4, and $6.23 \mathrm{~kg} / \mathrm{day}$, respectively. Significant quadratic effects were observed for the apparent total tract digestibilities of DM, OM, CP, and EE with estimated minimum digestibilities of $60.33,61.58,61.89$, and $55.83 \%$ for the levels of $44.80,47.18,50.95$, and $51.21 \%$ of sorghum silage in the forage portion of the diet, respectively. Mean daily weight gain and feed conversion also were affected quadratically by increasing the level of sorghum silage in the forage portion of the diet with estimated maximum and minimum values of $1.25 \mathrm{~kg} / \mathrm{day}$ and 7.66 for the levels of 60.95 and $67.04 \%$ of sorghum silage, respectively. Results indicated that varying dietary ratios of Tifton 85 haylage and sorghum silage is a good alternative for feeding forage to finishing beef cattle. Inclusion of approximately $60 \%$ of sorghum silage in the total dietary forage resulted in the greatest estimated weight gain.
}

Key Words: carcass yield, feed conversion, feedlot, roughage 


\section{Introdução}

O confinamento de bovinos de corte pode considerado uma estratégia alimentar e gerencial para a fase de engorda dos animais, com o propósito de melhorar a produtividade e a rentabilidade da exploração.

Estudos sobre a fonte de volumoso a ser utilizada neste sistema são fundamentais, pois, na maioria dos casos, a proporção de volumoso pode representar a maior parte da dieta dos animais. O sorgo se destaca pela possibilidade de se cultivar a rebrota, cuja produção pode atingir até $60 \%$ da obtida no primeiro corte (Zago, 1991). Além disso, possui maior tolerância à seca e ao calor e não é utilizado na alimentação humana. A cultura de sorgo é uma das que mais cresce no País, adquirindo importância estratégica no abastecimento de grãos e forragem, podendo contribuir para o equilíbrio dos estoques reguladores de grãos, reduzir os custos e permitir maior competitividade ao setor (Zago, 1999), visto que o Brasil é um dos países com maior potencialidade de adaptação e crescimento da cultura de sorgo no mundo (Zago, 1991).

O estádio de maturação da planta no momento da ensilagem é de essencial para o processo fermentativo. $\mathrm{O}$ ponto ideal de colheita é aquele em que a planta possui máximo teor de matéria seca, máximo potencial de consumo e digestibilidade e teor de MS capaz de assegurar um bom processo de fermentação para que as perdas sejam reduzidas, o valor nutritivo da silagem seja maximizado e a compactação seja adequada (Zago, 1999). O sorgo é ensilado geralmente no estádio de grãos pastosos a farináceos, quando as plantas já completaram seu ciclo de crescimento e apresentam em torno de 27 a $38 \%$ de MS (Faria, 1986; Zago, 1991).

Por outro lado, cultivares e híbridos do gênero Cynodon têm merecido destaque pela boa produtividade e pelo elevado valor nutritivo. Recentemente, foi selecionado o híbrido tifton 85 (Cynodon spp.), cruzamento do capimtifton 68 (Cynodon nlemfuensis Vanderyst) com uma introdução proveniente da África do sul, registro PI 290884 [Cynodon dactylon (L.) Pers.]. Por apresentar alta produção de MS, elevado valor nutritivo e rápida taxa de crescimento, além de colmos finos, o capim-tifton 85 pode ser utilizado para produção de feno e de silagem.

Considerando que para produção de feno é necessário colher a forrageira em dias ensolarados para desidratação das plantas, o processo de fenação apresenta um sério entrave, uma vez que o momento ideal para o corte das forrageiras, algumas vezes, coincide com dias chuvosos consecutivos. Acredita-se que, com a adoção dessa estra- tégia de manejo do campo de feno, evita-se a presença de forragem envelhecida e aumenta-se a possibilidade de produção de volumoso de boa qualidade.

A silagem de capim possui algumas vantagens interessantes, como elevada produção anual por área, possibilidade de menor custo por tonelada de MS produzida, perenidade, baixo risco de perda e maior flexibilidade de colheita. Em contrapartida, possuem também alguns aspectos desfavoráveis à ensilagem, como baixo teor de carboidratos solúveis, baixo teor de MS no momento do corte, alto poder tampão, que dificultam a fermentação adequada, e menor teor energético em comparação ao milho e ao sorgo (Balsalobre et al., 2001; Vilela \& Carneiro, 2002).

Embora na literatura constem trabalhos sobre a ensilagem de gramíneas do gêneroCynodon (Kunkle etal., 1988; Staples et al., 1993; Corsi \& Martha Jr., 1998; Evangelista et al., 2000), a maioria tem sido conduzida em silos laboratoriais, indicando, portanto, a necessidade de avaliações com animais.

Silagens de sorgo e capim-tifton 85 podem ser utilizadas como alternativa de volumosos no período da seca, de forma conjunta ou isolada, mas são escassas as pesquisas envolvendo a avaliação destes alimentos em associação.

Objetivou-se avaliar o consumo e a digestibilidade dos nutrientes, o ganho de peso, a conversão alimentar e o rendimento de carcaça em bovinos de corte recebendo dietas contendo níveis crescentes de pré-secado de capimtifton 85 em substituição à silagem de sorgo.

\section{Material e Métodos}

O experimento foi realizado nas dependências da Central de Experimentação, Pesquisa e Extensão do Triângulo Mineiro - CEPET, da Universidade Federal de Viçosa, no período de julho a outubro de 2000. Foram utilizados 24 animais mestiços Holandês x Zebu, não-castrados (360 kg de PV inicial), provenientes de rebanhos leiteiros da região. Após serem pesados e vermifugados, os animais foram distribuídos em baias individuais de aproximadamente $10 \mathrm{~m}^{2}$, com cocho coberto e bebedouro, em um delineamento em blocos casualizados, constituindo seis blocos completos, quatro tratamentos e seis animais por tratamento.

As dietas, isonitrogenadas, foram formuladas para conter aproximadamente $12 \%$ de $\mathrm{PB}$ e uma relação volumoso:concentrado de 60:40. Como fonte de volumoso utilizaram-se pré-secado de capim-tifton 85 e silagem de sorgo do híbrido forrageiro AG 2002 (Agroceres) nas proporções 100:0; 68:32; 34:66 e 0:100, respectivamente, com base na MS. 
O sorgo foi estabelecido em áreas da CEPET, conforme recomendações de plantio do produtor de sementes. A correção do solo foi realizada com base nos resultados da análise de solo, segundo as "Recomendações para o uso de corretivos e fertilizantes em Minas Gerais" (CFSEMG, 1989). A ensilagem do sorgo foi feita em silos tipo superfície quando os grãos atingiram o estádio farináceo-duro. Para obtenção do pré-secado, o capim-tifton 85 foi colhido quando se encontrava em estádio avançado de maturidade (maturidade plena), utilizando-se uma segadora-condicionadora. $\mathrm{O}$ capim foi mantido enleirado no campo por 2 a 3 horas, até atingir aproximadamente 50\% de MS. Em seguida, foi recolhido e picado em maquinário específico para estas operações, sendo ensilado em um silo tipo trincheira.

As proporções dos ingredientes do concentrado encontram-se na Tabela 1. As composições bromatológicas do concentrado, do pré-secado e da silagem de sorgo são descritas na Tabela 2 e as das dietas na Tabela 3. Após um período de adaptação de 15 dias, foram realizados três períodos experimentais de 28 dias. Os animais foram pesados após jejum de 16 horas no início e no final do experimento, efetuando-se pesagens intermediárias ao final de cada período. O volumoso e o concentrado foram fornecidos diariamente, juntos e misturados, metade às $8 \mathrm{~h}$ e metade às $15 \mathrm{~h}$, permitindo-se sobras de $10 \%$ do ofertado. Durante o ensaio, foram coletadas amostras diárias dos alimentos fornecidos e das sobras, obtendo-se uma amostra composta para cada período, as quais foram acondicionadas em sacos plásticos identificados e armazenadas em congelador a $-18^{\circ} \mathrm{C}$.

Do $39 \underline{0}$ ao $43 \underline{0}$ dia experimental, antes da primeira alimentação, foram coletadas fezes frescas dos animais, diretamente no piso(raspado diariamente), com o cuidado para não contaminar as amostras com fezes secas, urina ou solo. Neste período, também foram coletadas amostras dos alimentos fornecidos e das sobras.

Tabela 1 - Participação dos ingredientes no concentrado Table 1 - Ingredient composition of the concentrate

\begin{tabular}{lc}
\hline $\begin{array}{l}\text { Ingrediente } \\
\text { Ingredient }\end{array}$ & $\begin{array}{c}\% \text { na matéria natural } \\
\% \text { as-fed basis }\end{array}$ \\
\hline Fubá de milho (Corn meal) & 62,80 \\
Grão de soja moído (Ground whole soybean) & 34,94 \\
Fosfato bicálcico (Dicalcium phosphate) & 0,27 \\
Sal (Salt) & 0,39 \\
Calcário calcítico (Limestone) & 0,67 \\
Uréia (Urea) & 0,80 \\
Sulfato de amônia (Ammonium sulfate) & 0,10 \\
Premix ${ }^{1}$ (Mix) & 0,03 \\
\hline 181,5\%de sulfato de zinco (zinc sulfate); 17,52\% de sulfato de cobre (cupper \\
sulfate); 0,48\% de iodato de potássio (potassiumiodate); 0,32\% de selenito de \\
sódio (sodium selenite); e 0,18\% de sulfato de cobalto (cobalt sulfate).
\end{tabular}

Ao final do período experimental, todas as amostras foram submetidas à pré-secagem em estufa de ventilação forçada a $65^{\circ} \mathrm{C}$, por 72 horas, sendo trituradas em moinho de faca tipo Willey com peneira de 30 mesh e armazenadas em recipientes de vidro com tampa de polietileno, para futuras análises laboratoriais.

Tabela 2 - Teores médios de nutrientes do concentrado, do présecado de capim-tifton 85 e da silagem de sorgo utilizados nas dietas experimentais (\% da MS), nitrogênio amoniacal $\left(\mathrm{N}-\mathrm{NH}_{3}\right)$ da silagem de sorgo e $\mathrm{pH}$ do pré-secado de capim-tifton 85 e da silagem de sorgo

Table 2 - Chemical composition of the concentrate, Tifton 85 haylage, and sorghum silage, ammonia nitrogen $\left(\mathrm{NH}_{3}-\mathrm{N}\right)$ content of the sorghum silage, and $\mathrm{pH}$ of Tifton 85 haylage and sorghum silage used in the experimental diets

\begin{tabular}{|c|c|c|c|}
\hline $\begin{array}{l}\text { Item } \\
\text { Item }\end{array}$ & $\begin{array}{c}\text { Concentrado } \\
\text { Concentrate }\end{array}$ & $\begin{array}{c}\text { Pré-secado } \\
\text { Haylage }\end{array}$ & $\begin{array}{l}\text { Silagem de sorgo } \\
\text { Sorghum silage }\end{array}$ \\
\hline $\operatorname{MS}(\%)(D M, \%)$ & 89,79 & 53,65 & 24,44 \\
\hline $\mathrm{MO}(O M)$ & 96,96 & 93,56 & 95,59 \\
\hline $\mathrm{PB}(C P)$ & 21,25 & 5,99 & 6,13 \\
\hline $\operatorname{NIDN}^{1}(N D I N)$ & 10,29 & 42,15 & 26,99 \\
\hline $\operatorname{NIDA}^{1}(A D I N)$ & 6,56 & 31,00 & 16,43 \\
\hline $\mathrm{EE}(E E)$ & 9,59 & 1,85 & 2,46 \\
\hline $\mathrm{CT}(T C)$ & 66,12 & 85,71 & 87,01 \\
\hline FDN $(N D F)$ & 12,66 & 78,37 & 54,14 \\
\hline FDNcp (NDFap) & 11,55 & 75,47 & 52,30 \\
\hline $\mathrm{CNF}(N F C)$ & 53,47 & 7,34 & 32,87 \\
\hline FDA $(A D F)$ & 6,51 & 44,67 & 38,92 \\
\hline FDAi $(I A D F)$ & 0,72 & 17,20 & 15,53 \\
\hline HEM & 6,15 & 33,70 & 15,22 \\
\hline LIG & 2,48 & 7,51 & 8,00 \\
\hline $\mathrm{N}-\mathrm{NH}_{3}{ }^{1}$ & - & - & 3,05 \\
\hline $\mathrm{pH}$ & - & 4,37 & 3,83 \\
\hline
\end{tabular}

$1 \%$ do $\mathrm{N}$ total.

$1 \%$ total $N$.

Tabela 3 - Composição química das dietas experimentais (\% da MS)

Table 3 - Chemical composition of experimental diets (\% of DM)

Item Nível de silagem de sorgo no volumoso (\%)

Item Level of sorghum silage in the forage portion of the diet (\%)

\begin{tabular}{|c|c|c|c|c|}
\hline & & & & \\
\hline & 0 & 32 & 66 & 100 \\
\hline $\operatorname{MS}(\%)(D M, \%)$ & 67,96 & 62,38 & 56,39 & 50,32 \\
\hline $\mathrm{MO}(O M)$ & 94,90 & 95,29 & 95,71 & 96,13 \\
\hline $\mathrm{PB}(C P)$ & 12,03 & 12,06 & 12,08 & 12,11 \\
\hline $\operatorname{NIDN}^{1}(N D I N)$ & 12,75 & 11,34 & 9,83 & 8,32 \\
\hline $\operatorname{NIDA}^{1}(A D I N)$ & 10,67 & 8,00 & 6,54 & 5,06 \\
\hline $\mathrm{EE}(E E)$ & 4,92 & 5,03 & 5,16 & 5,28 \\
\hline $\mathrm{CT}(T C)$ & 77,96 & 78,20 & 78,47 & 78,74 \\
\hline $\mathrm{FDN}(N D F)$ & 52,35 & 47,72 & 42,74 & 37,71 \\
\hline FDNcp (NDFap) & 50,16 & 45,73 & 40,98 & 36,16 \\
\hline $\mathrm{CNF}^{1}(N F C)$ & 25,61 & 30,48 & 35,72 & 41,03 \\
\hline FDA $(A D F)$ & 29,56 & 28,46 & 27,28 & 26,08 \\
\hline FDAI $(I A D F)$ & 10,67 & 10,35 & 10,01 & 9,66 \\
\hline HEM & 22,79 & 19,26 & 15,47 & 11,63 \\
\hline LIG & 5,52 & 5,61 & 5,71 & 5,82 \\
\hline $\operatorname{NDT}(T D N)$ & 64,27 & 65,05 & 65,40 & 67,61 \\
\hline
\end{tabular}

$1 \%$ do $\mathrm{N}$ total.

$1 \%$ total $N$. 
Ao final do experimento, a composição químicobromatológica de todas as amostras foi determinada no Laboratório de Nutrição Animal do Departamento de Zootecnia da UFV, em Viçosa, segundo procedimentos descritos por Silva \& Queiroz (2002). Os carboidratos totais (CT) foram calculados segundo metodologia da Universidade de Cornell, descrita por Sniffen et al. (1992), em que: $\mathrm{CT}(\%)=100-(\% \mathrm{~PB}+\% \mathrm{EE}+\%$ Cinzas $)$, e o NDT dos alimentos foi estimado segundo equação proposta por Weiss (1999): NDT = PBD + 2,25 x EED + FDNcpD + CNFD, em que: PBD, EED, FDN e CNFD significam, respectivamente, $\mathrm{PB}$ digestível, EE digestível, FDN digestível e CNF digestíveis. Os carboidratos não-fibrosos (CNF) foram calculados por meio da diferença entre CT e FDN.

O indicador interno FDAi foi utilizado para estimativa da produção de matéria seca fecal (MSF), conforme proposto por Cochran et al. (1986). Entretanto, adotou-se a incubação in situ - as amostras compostas de alimentos fornecidos, sobras e fezes foram incubadas no rúmen, em sacos de ankom (filter bags 57), durante 144 horas - em vez de se utilizar a digestibilidade in vitro sugerida pelos autores. O material resultante desta incubação foi submetido à digestão com detergente ácido e o resíduo foi considerado FDAi. O total de MSF foi calculado segundo a equação: kg de MSF estima$\mathrm{da}=\mathrm{kg}$ de indicador ingerido/\% do indicador nas fezes.

Os dados foram submetidos às análises de variância e regressão utilizando-se o programa SAEG (UFV, 2000). Os modelos foram escolhidos com base na significância dos coeficientes de regressão, utilizando-se o teste t a 10 e $1 \%$ de probabilidade, no coeficiente de determinação e no fenômeno biológico.

\section{Resultados e Discussão}

Os resultados referentes aos consumos médios diários dos nutrientes, os respectivos coeficientes de variação e determinação e as equações de regressão obtidas em função dos níveis de silagem de sorgo no volumoso da dieta são apresentados na Tabela 4 . O consumo de MS, em kg/dia, não foi influenciado pelas dietas e apresentou valor médio de 9,46. Silva et al. (2005), ao fornecerem silagem de Brachiaria brizantha para bovinos de corte, verificaram aumento linear no consumo de MS com o aumento da participação de concentrado na dieta. Todavia, dietas contendo menos que $50 \%$ de concentrado limitaram o consumo de nutrientes e, conseqüentemente, o ganho de peso dos animais. Segundo esses autores, esta limitação possivelmente foi ocasionada pelos produtos finais da fermentação. Chizzotti et al. (2005) verificaram aumento linear no consumo de MS com a substituição da silagem de Brachiaria brizantha por silagem de sorgo. Segundo Nussio et al. (2003), práticas associadas à redução da umidade presente na forragem, antecedendo a ensilagem, podem estimular o consumo de MS.

O consumo de volumosos com menor conteúdo de água, como o pré-secado e o feno, podem ser limitados pela quantidade de saliva necessária para seu umedecimento e sua posterior deglutição (Luginbuhl et al., 2000). Todavia, o consumo de silagem pode ser limitado pelos produtos da fermentação (ácidos acético e lático), pela mudança na estrutura física do material ensilado, pela degradação da proteína e pela redução do pH (Erdman, 1993). Portanto, a associação do pré-secado à silagem consiste em alternativa para minimização destes problemas.

O consumo de MS, em \%PV, decresceu linearmente com o aumento da proporção de silagem de sorgo no volumoso, estimando-se redução de 0,001 unidades por unidade de acréscimo de silagem de sorgo. Este declínio pode estar relacionado à redução do conteúdo de MS das dietas com a adição de silagem de sorgo (Tabela 3 ) e, possivelmente, ao maior peso médio dos animais deste tratamento, que ganharam mais peso, o que contribui para menor consumo de MS quando expresso em \%PV. Neumann et al. (2000) verificaram consumo de $2,17 \% \mathrm{PV}$ para bovinos de corte recebendo dieta contendo silagem de sorgo do híbrido AG 2002 e Costa et al. (2002) encontraram consumo médio de $2,36 \% \mathrm{PV}$ para animais zebus alimentados com pré-secado de capim-tifton 85 e diferentes níveis de concentrado. Feijó et al. (2001), trabalhando com vacas de descarte recebendo silagem de sorgo ou de capim-mombaça, observaram con sumos médios de 2,8 e 2,2\% PV, respectivamente.

Os consumos de MO, PB, EE e CT, expressos em kg/dia, não foram influenciados pelas dietas, registrando-se valores médios de 9,05; 1,20; 0,52 e 7,34 kg/dia, respectivamente (Tabela 4), o que era esperado, tendo em vista a similaridade entre as dietas, pois não ocorreram diferenças no consumo de MS expresso em $\mathrm{kg} / \mathrm{dia}$.

O consumo de FDN, expresso nas diferentes formas, diminuiu de forma linear com o aumento da proporção de silagem de sorgo no volumoso, o que, provavelmente, foi conseqüência da redução do teor de FDN das dietas com o aumento da proporção de silagem de sorgo no volumoso (Tabela 3).

De forma similar ao observado por Chizzotti et al. (2005), o consumo de CNF aumentou linearmente com o incremento da proporção de silagem de sorgo no volumoso, sendo estimados acréscimos de $0,014 \mathrm{~kg} /$ dia por unidade de acréscimo de silagem de sorgo. Este aumento foi ocasio- 
Tabela 4 - Consumos médios diários de nutrientes, coeficientes de variação (CV), respectivas equações de regressão ajustadas em função da proporção de silagem de sorgo no volumoso das dietas e coeficientes de determinação $\left(r^{2}\right)$

Table 4 - Average daily intake of nutrients, coefficients of variation (CV), fitted regression equations, and coefficients of determination $\left(r^{2}\right)$ according to increasing levels of sorghum silage in the diet

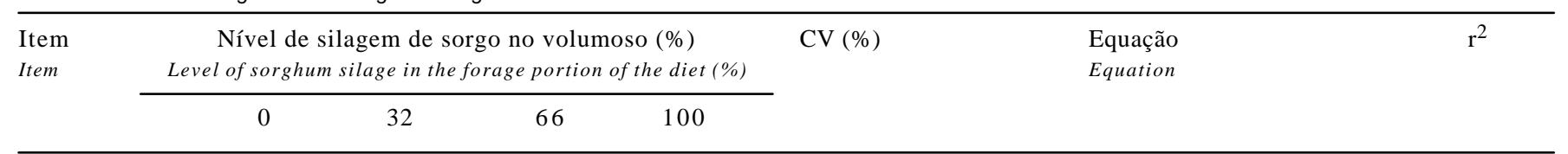

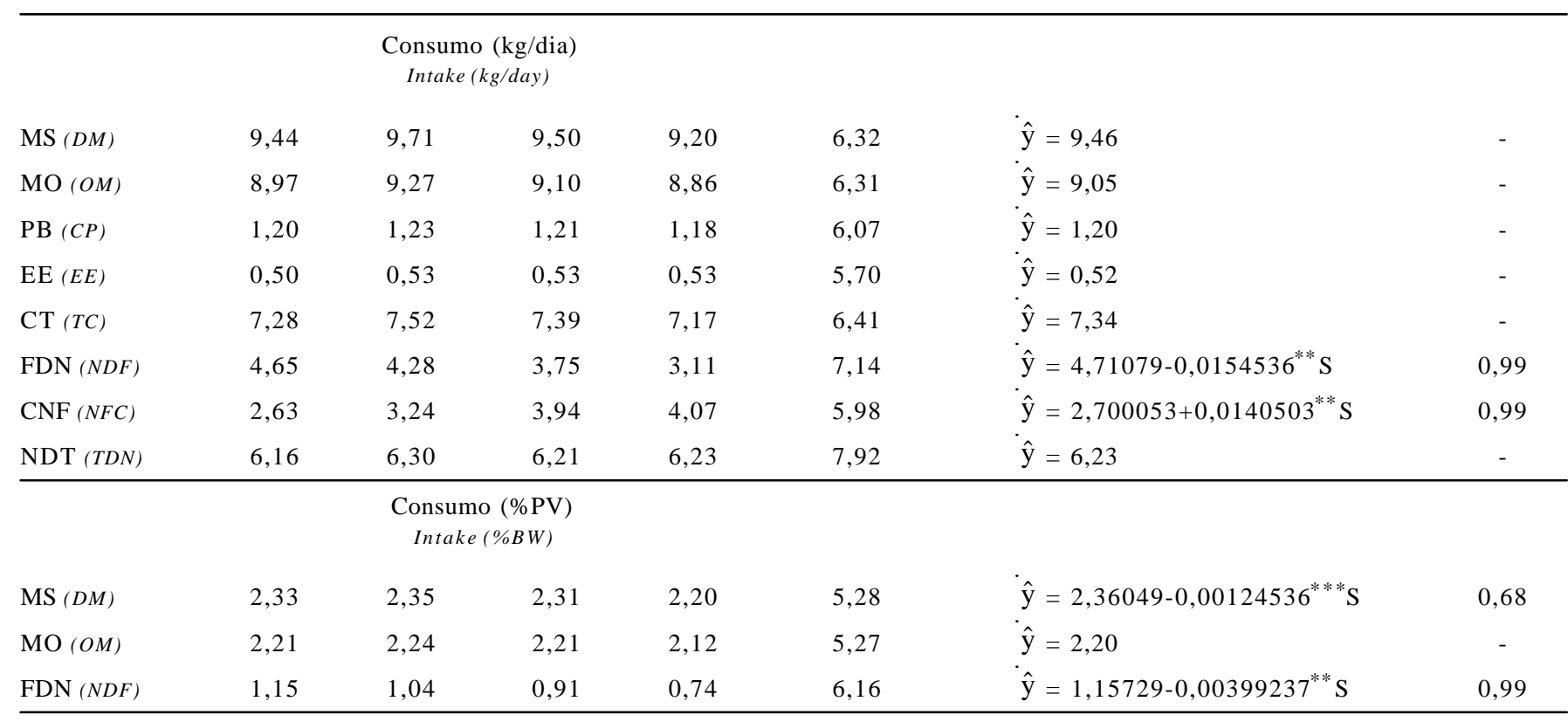

** $(P<0,01) ;{ }^{* \star *}(P<0,10)$.

nado pela elevação expressiva no conteúdo de CNF das dietas (Tabela 3), visto que os consumos de MS foram semelhantes.

O consumo de NDT não foi influenciado pelos tratamentos, indicando similaridade entre as dietas, cujo valor médio foi de $6,23 \mathrm{~kg} / \mathrm{dia}$. Os consumos de PB e NDT superaram as exigências destes animais para ganhos de $1 \mathrm{~kg}$ de PV, que, segundo o NRC (1996), são de 0,916 e 5,8 kg/dia, respectivamente.

As digestibilidades aparentes médias dos nutrientes, os respectivos coeficientes de variação e determinação e as equações de regressão são apresentados na Tabela 5. As digestibilidades aparentes da MS e da MO foram influenciadas de forma quadrática pelo aumento na proporção de silagem de sorgo no volumoso, apresentando valores mínimos de 60,33 e $61,58 \%$, respecitvamente, para dietas contendo 44,80 e $47,18 \%$ de silagem de sorgo.

Bovinos alimentados com dietas à base de alimentos volumosos mais secos gastam mais tempo com atividade de mastigação e salivação até a ingestão (Clancy et al., 1977), o que, possivelmente, acarretaria menor taxa de passagem e, conseqüentemente, maior digestibilidade. Segundo Beauchemin \& Buchanan-Smith (1990), são esperadas maiores digestibilidades para dietas contendo silagem, em comparação a dietas contendo feno, pois, no processo de digestão dessas dietas, ocorre maior desintegração das partículas da silagem em menor tempo, resultando em maior taxa de passagem. Desta forma, à medida que se aumentaram os níveis de silagem de sorgo no volumoso, observou-se aumento na digestibilidade das dietas.

As digestibilidades aparentes da PB e EE também foram influenciadas de forma quadrática pela proporção de silagem de sorgo no volumoso, sendo estimadas digestibilidades mínimas de 61,89 e 55,83\%, respectivamente, para dietas contendo 50,95 e 51,21\% de silagem de sorgo no volumoso. As digestibilidades aparentes dos CT e CNF não foram influenciadas pelos níveis de silagem de sorgo no volumoso, registrando-se valores médios de 63,10 e 76,92\%, respectivamente (Tabela 5).

A digestibilidade da FDN foi influenciada de forma linear pela proporção de silagem de sorgo no volumoso, apresentando decréscimos de 0,059 unidades por unidade de acréscimo de silagem de sorgo no volumoso, atribuídos à qualidade inferior da FDN da silagem de sorgo em comparação à do pré-secado de capim-tifton (Tabela 2). Cavalcante et al. (2004), em experimento com animais canulados no 
Tabela 5 - Médias, coeficientes de variação, respectivas equações de regressão ajustadas em função da proporção de silagem de sorgo no volumoso da dieta e coeficientes de determinação $\left(\mathrm{r}^{2} / \mathrm{R}^{2}\right)$ para as digestibilidades de nutrientes da dieta

Table 5 - Means, coefficients of variation (CV), fitted regression equations, and coefficients of determination $\left(r^{2} / R^{2}\right)$ for apparent total tract digestibility of nutrients according to increasing levels of sorghum silage in the diet

\begin{tabular}{|c|c|c|c|c|c|c|c|}
\hline \multirow[t]{2}{*}{$\begin{array}{l}\text { Item } \\
\text { Item }\end{array}$} & \multicolumn{4}{|c|}{$\begin{array}{l}\text { Nível de silagem de sorgo no volumoso (\%) } \\
\text { Level of sorghum silage in the forage portion of the diet (\%) }\end{array}$} & \multirow[t]{2}{*}{$\mathrm{CV}(\%)$} & \multirow[t]{2}{*}{$\begin{array}{l}\text { Equação } \\
\text { Equation }\end{array}$} & \multirow[t]{2}{*}{$r^{2} / R^{2}$} \\
\hline & 0 & 32 & 66 & 100 & & & \\
\hline $\mathrm{MO}(O M)$ & 64,98 & 60,03 & 63,80 & 64,44 & 4,79 & $\hat{y}=64,3333-0,116576^{\mathrm{ns}} S+0,0012354^{*} \mathrm{~s}^{2}$ & 0,52 \\
\hline $\mathrm{PB}(C P)$ & 67,12 & 61,25 & 63,57 & 65,90 & 5,11 & $\hat{y}=66,6607-0,187292^{\mathrm{ns}} S+0,001838^{* *} S^{2}$ & 0,82 \\
\hline $\mathrm{CT}(T C)$ & 64,05 & 60,44 & 63,90 & 64,00 & 4,28 & $\hat{\mathrm{y}}=63,10$ & \\
\hline $\operatorname{FDN}(N D F)$ & 56,45 & 52,04 & 50,71 & 50,56 & 7,18 & $\hat{y}=55,2936-0,0591902^{* *} S$ & 0,82 \\
\hline $\mathrm{CNF}(N F C)$ & 77,73 & 72,56 & 79,50 & 77,91 & 5,18 & $\hat{y}=76,92$ & \\
\hline
\end{tabular}

${ }^{*}(\mathrm{P}<0,05) ;{ }^{* *}(\mathrm{P}<0,01)$.

Tabela 6 - Médias de ganho de peso (GMD), conversão alimentar (CA) e rendimento de carcaça (RC), coeficientes de variação e respectivas equações de regressão, ajustadas em função da proporção de silagem de sorgo no volumoso das dietas, e coeficientes de determinação $\left(r^{2} / R^{2}\right)$

Table 6 - Means, coefficients of variation (CV), fitted regression equations, and coefficients of determination $\left(r^{2} / R^{2}\right)$ for weight gain $(W G)$, feed conversion (FC), and carcass yield (CY) according to increasing levels of sorghum silage in the diet

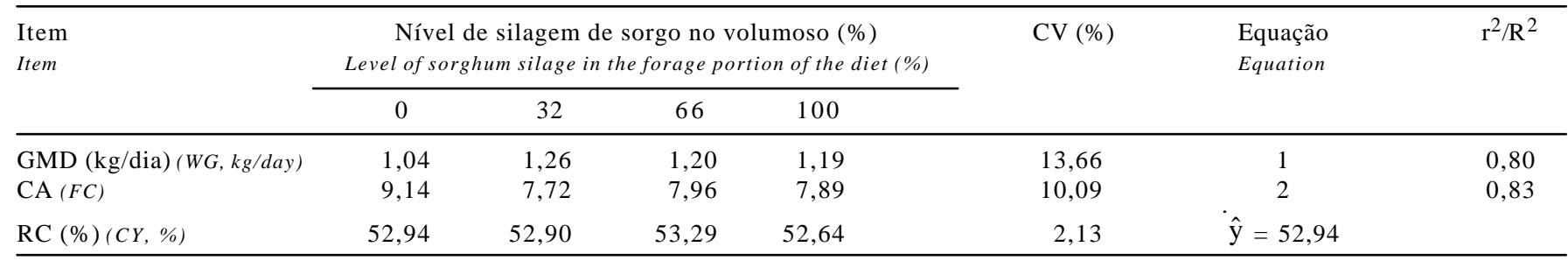

* $(\mathrm{P}<0,05) ;{ }^{* * *}(\mathrm{P}<0,10)$.

$1-\hat{\mathrm{y}}=1,05335+0,0066026^{\mathrm{ns}} \mathrm{S}-0,00005416^{* * *} \mathrm{~S}^{2}$.

$2-\hat{\mathrm{y}}=9,03021-0,0408928^{*} \mathrm{~S}+0,000305109^{* * *} \mathrm{~S}^{2}$.

rúmen recebendo dietas contendo silagem de milho e feno de capim-tifton 85 em diferentes proporções, estimaram digestibilidade da FDN máxima de $65,2 \%$ para dietas contendo $30,98 \%$ de silagem de milho.

$\mathrm{Na}$ Tabela 6 constam as médias de ganhos de peso (GP), conversão alimentar (CA) e rendimento de carcaça (RC), os respectivos coeficientes de variação e determinação e as equações de regressão obtidas para os diferentes níveis de silagem de sorgo na dieta. O GMD foi influenciado de forma quadrática pelo nível de silagem de sorgo no volumoso, estimando-se ganho máximo de $1,25 \mathrm{~kg} / \mathrm{dia}$, para dietas contendo $60,95 \%$ de silagem de sorgo. O desempenho animal é primeiramente definido pelo consumo voluntário, que determina a quantidade de nutrientes ingeridos (Van Soest, 1994). Segundo Mertens (1994), 60 a $90 \%$ das variações no desempenho animal são decorrentes das oscilações no consumo de nutrientes e apenas 10 a $40 \%$ são ocasionadas pelas mudanças na digestibilidade. Essa afirmativa pode explicar o comportamento desta variável, pois o consumo de MS não variou entre as dietas, ao passo que a digestibilidade deste constituinte, conforme demonstrado anteriormente, variou de forma quadrática.

Chizzotti et al. (2005), ao avaliarem dietas contendo silagens de Brachiaria brizantha e sorgo em diferentes proporções no volumoso em dietas para bovinos de corte, verificaram aumento linear no GMD com o aumento da silagem de sorgo no volumoso.

De forma similar, a CA também foi influenciada pelo nível de silagem de sorgo no volumoso, estimando-se valor mínimo de 7,66 para dietas contendo $67,01 \%$ de silagem de sorgo no volumoso. Este valor foi próximo ao nível de silagem de sorgo que resultou em maior GMD. 
Semelhantemente ao observado por Chizzotti et al. (2005), o RC neste estudo não foi influenciado pelas dietas experimentais e apresentou valor médio de $52,94 \%$.

Ouso de silagem de sorgo associada ao pré-secado de capim-tifton 85 mostrou-se uma boa alternativa de alimento volumoso para terminação de bovinos de corte em confinamento. Este resultado demonstra a possibilidade de redução de custos com alimentação, visto que o custo de produção do pré-secado é inferior ao da silagem de sorgo, possibilitando maior flexibilidade no programa de suplementação alimentar do rebanho.

\section{Conclusões}

O uso de pré-secado de capim-tifton 85 associado à silagem de sorgo apresentou-se uma boa alternativa de volumoso para terminação de bovinos de corte.

A inclusão de aproximadamente $60 \%$ de silagem de sorgo no volumoso promoveu máximo ganho de peso estimado.

\section{Literatura Citada}

BALSALOBRE, M.A.A.; NUSSIO, L.G.; MARTHA JR., G.B. Controle de perdas na produção de silagens de gramíneas tropicais. In: REUNIÃO ANUAL DA SOCIEDADE BRASILEIRA DE ZoOteCniA, 38., 2001, Piracicaba. Anais... Piracicaba: Sociedade Brasileira de Zootecnia, 2001. p.890-911.

BEAUCHEMIN, K.A.; BUCHANAN-SMITH, J.G. Effects of fiber source and method of feeding on chewing activities, digestive function, and productivity of dairy cows. Journal of Dairy Science, v.73, n.3, p.749-762, 1990.

CHIZZOTTI, F.H.M.; PEREIRA, O.G.; VALADARES FILHO, S.C. et al. Consumo, digestibilidade total e desempenho de novilhos Nelore recebendo dietas contendo diferentes proporções de silagens de Brachiaria brizantha cv. Marandu e de sorgo. Revista Brasileira de Zootecnia, v.34, n.6, p.2427-2436, 2005.

CLANCY, M.; WANGNESS, P.J.; BAUMGARDT, B.R. Effect of conservation method on digestibility, nitrogen balance, and intake of alfalfa. Journal of Animal Science, v.60, p.572579, 1977.

COCHRAN, R.C.; ADAMS, D.C.; WALACE, J.D. et al. Predicting digestibility of different diets with internal markers: evaluation of four potential markers. Journal of Animal Science, v.63, n.5, p.1476-1483, 1986.

CAVALCANTE, A.C.R.; PEREIRA, O.G.; VALADARES FILHO, S.C. et al. Dietas contendo silagem de milho (Zea maiz L.) e feno de capim-Tifton 85 (Cynodon spp.) em diferentes proporções para bovinos. Revista Brasileira de Zootecnia, v.33, n.6, p.2394-2402, 2004.

COMISSÃO DE FERTILIDADE DO SOLO DO ESTADO DE MINAS GERAIS - CFSEMG. Recomendações para uso de corretivos e fertilizantes em Minas Gerais. 4a Aproximação. Lavras, 1989. $159 \mathrm{p}$.

CORSI, M.; MARTHA JR., G.B. Manejo de pastagens para produção de carne e leite. In: SIMPÓSIO SOBRE MANEJO DE PASTAJEM, 15., 1998, Piracicaba. Anais... Piracicaba: Fundação de Estudos Agrários Luiz de Queiroz, 1998. p.55-83.

COSTA, M.L.; VALADARES FILHO, S.C.; PAULINO, M.F. et al. Desempenho produtivo de novilhos zebu alimentados com diets contendo diferentes níveis de concentrado. In: REUNIÃO ANUAL DA SOCIEDADE BRASILEIRA DE ZOOTECNIA, 39., 2002, Recife. Anais... Recife: Sociedade Brasileira de Zootecnia. (CD ROM).

ERDMAN, R. Silage fermentation characteristics affecting feed intake. In: NATIONAL SILAGE PRODUCTION CONFERENCE, 1993, Syracuse. Proceedings... Syracuse: NRAES-67, 1993. p. 210.

EVANGELISTA, A.R.; LIMA, J.A.; BERNARDES, T.F. Avaliação de algumas características da silagem de gramímea estrela roxa (Cynodon nlemfuensis Vanderyst). Revista Brasileira de Zootecnia, v.29, n.4, p.941-946, 2000.

FARIA, V.P. Técnicas de produção de silagens. In: CONGRESSO BRASILEIRO DE PASTAGENS, 8., 1986. Piracicaba.Anais... Piracicaba: Fundação de Estudos Agrários Luiz de Queiroz, 1986. p.79-144.

FEIJÓ, G.L.D.; THIAGO, L.R.L.S.; SILVA, J.M. et al. Uso de silagens e concentrados, contendo milho ou casca de soja, para engorda de vacas de descarte em confinamento. In: REUNIÃO ANUAL DA SOCIEDADE BRASILEIRA DE ZOOTECNIA, 38., 2001, Piracicaba. Anais... Piracicaba: Sociedade Brasileira de Zootecnia, 2001. p.1108-1109.

KUNKLE, W.E.; BATES, D.B.; CHAMBLISS, C.G. et al. Alternative forage storage-bale silage. In: DAIRY HERD MANAGEMENT CONFERENCE, 1988, Athens. Proceedings... Athens: University of Georgia, 1988. p.31-41.

LUGINBUHL, J.M.; POND, K.R.; BURNS, J.C. et al. Intake and chewing behavior of steers consuming switchgrars preserved as hay or silage. Journal of Animal Science, v.78, n.7, p. 1983-1989, 2000.

MERTENS, D.R. Regulation of forage intake. In: FAHEY Jr., G.C. (Ed.) Forage quality, evaluation and utilization. Madison: American Society of Agronomy: 1994. p.450-493.

NATIONAL RESEARCH COUNCIL - NRC. Nutrient requirements of beef cattle. 7.ed. Washington, D.C.: National Academy, 1996. 242p.

NEUMANN, M.; RESTLE, J.; ALVES FILHO, D.C. et al. Avaliação de diferentes híbridos de sorgo (Sorghum bicolor L. MOENCH) para produção de silagem. IV. Desempenho de novilhos confinados. In: REUNIÃO ANUAL DA SOCIEDADE BRASILEIRA DE ZOOTECNIA, 37., 2000, Viçosa, MG. Anais... Viçosa, MG: Sociedade Brasileira de Zootecnia, 2000. (CD ROM).

NUSSIO, L.G.; RIBEIRO, J.L.; PAZIANI, S.F. et al. Fatores que interferem no consumo de forragens conservadas. In: REIS, R.A.; BERNARDES, T.F.; SIQUEIRA, G.R. et al. (Eds). Volumosos na produção de ruminantes: valor alimentício de forragens. Jaboticabal: Editora Funep, 2003. p.27-50.

SILVA, B.C.; PEREIRA, O.G.; PEREIRA, D.H. et al. Consumo e digestibilidade aparente total dos nutrientes e ganho de peso de bovinos de corte alimentados com silagem de Brachiaria brizantha e concentrado em diferentes proporções. Revista Brasileira de Zootecnia, v.34, n.3, p.1060-1069, 2005.

SILVA, D.J.; QUEIROZ, A.C. Análises de alimentos (métodos químicos e biológicos). 3ed. Vi çosa, MG: Editora UFV, 2002. $235 \mathrm{p}$.

SNIFFEN, C.J.; O'CONNOR, J.D.; Van SOEST, P.J. et al. A net carbohydrate and protein system for evaluating cattle diets. II. Carbohydrate and protein availability. Journal of Animal Science, v.70, n.11, p.3562-3577, 1992.

STAPLES, C.; RUIZ, T.; BERNAL, E. Feeding Bermudagrass silage to lactating dairy cows. In: INTERNATIONAL CONFERENCE ON LIVESTOCK IN THE TROPICS. 1993, Gainesville. Proceedings... Gainesville: University of Florida, Institute of Food and Agricultural Science, 1993. p.118-128.

UNIVERSIDADE FEDERAL DE VIÇOSA - UFV. SAEG - Sistema de análises estatísticas e genéticas. Versão 8.0. Viçosa, MG: 2000. (CD-ROM).

Van SOEST, P.J. Nutritional ecology of the ruminants. 2.ed. Ithaca: Cornell University, 1994. 476p. 
VILELA, D.; CARNEIRO, J.C. Ensilagem do excedente de pasto: uma alternativa para o manejo. In: SIMPÓSIO SOBRE MANEJO ESTRATÉGICO DE PASTAGENS, 1., 2002, Viçosa, MG. Anais... Viçosa, MG: Universidade Federal de Viçosa, 2002. p.331-350.

ZAGO, C.P. Cultura de sorgo para produção de silagem de alto valor nutritivo. In: SIMPÓSIO SOBRE NUTRIÇÃO DE BOVINOS, 4., 1991, Piracicaba. Anais... Piracicaba: Fundação de Estudos Agrários Luiz de Queiroz, 1991. p.169-217.

ZAGO, C.P. Silagem de sorgo. In: SIMPÓSIO SOBRE NUTRIÇÃO DE BOVINOS: ALIMENTAÇÃO SUPLEMENTAR, 7., 1999. Anais... Piracicaba: Fundação de Estudos Agrários Luiz de Queiroz, 1999. p.47-68.
WEISS, W.P. Energy prediction equations for ruminant feeds. In: CORNELL NUTRITION CONFERENCE FOR FEED MANUFACTURERS, 61., 1999, Ithaca. Proceedings... Ithaca: Cornell University, 1999. p.176-185.

Recebido: 19/09/05 Aprovado: 11/07/06 